\title{
Changing HIV Epidemic in North-Eastern India and Its Relationship with Development and Programmatic Indicators
}

\author{
Chiranjeev Bhattacharjya ${ }^{1^{*}}$, Sangram Kishor Patel2 ${ }^{2}$, Samiran Panda ${ }^{3}$, Alok Kr. Deb ${ }^{3}$ \\ ${ }^{1}$ Assam State AIDS Control Society, National AIDS Control Organization, Guwahati, India \\ ${ }^{2}$ HIV and AIDS Program, Population Council, New Delhi, India \\ ${ }^{3}$ National Institute of Cholera and Enteric Diseases, ICMR, Kolkata, India \\ Email: ${ }^{*}$ epiassam@gmail.com
}

Received 20 August 2015; accepted 22 September 2015; published 25 September 2015

Copyright (C) 2015 by authors and Scientific Research Publishing Inc.

This work is licensed under the Creative Commons Attribution International License (CC BY). http://creativecommons.org/licenses/by/4.0/

(c) (7) Open Access

\section{Abstract}

Background: Although there has been significant reduction in HIV prevalence and new HIV infections in India, some of the low/moderate prevalence states have been showing long term increase in HIV prevalence and new HIV infections. Assam, a state in northeast India is one such low HIV prevalence state where HIV prevalence and new HIV infections have almost doubled in the last few years. This study examined the trend of HIV prevalence across districts/regions of Assam and its association with developmental and program indicators. Materials and Methods: A retrospective descriptive analysis of secondary data from the National AIDS Control Program, Census of India2011, and District Level Household and Facility Survey-3 was conducted. The time period covered under the secondary data analysis was 2007 to 2012 . Correlation and Chi-square for trend tests were also used in this paper. Results: During 2007 and 2012, HIV positivity (\%) increased relatively in North Assam (46.9\%) followed by South Assam (11.5\%) while there has been a relative decline in West Assam (-51.5\%). Correlation analysis showed statistically significant association between HIV prevalence and female literacy, population using mobile phone, population using internet, women (15 - 49 years) seeking treatment for any STI/RTI, proportion of brothel based FSWs, FSWs having < 5 clients per week and proportion of condom utilized annually. Conclusion: Program efforts in the state should be focus on the districts with increasing HIV prevalence. Emphasis should be given in planning strategies to address the program gaps among the high risk and vulnerable populations in the state.

\section{Keywords}

HIV, Epidemic, Program and Development Indicator, North-Eastern India

\footnotetext{
${ }^{*}$ Corresponding author.
}

How to cite this paper: Bhattacharjya, C., Patel, S.K., Panda, S. and Deb, A. (2015) Changing HIV Epidemic in North-Eastern India and Its Relationship with Development and Programmatic Indicators. World Journal of AIDS, 5, 265-274. 


\section{Introduction}

Since the beginning of the HIV epidemic in 1981, significant success has been achieved in containing the epidemic globally through sustained preventive and curative efforts. However, pockets of emerging and concentrated HIV epidemics continue to exist in some regions. India has the third largest number of people living with HIV in the world-2.1 million (1.7 million - 2.7 million) by the end of 2013-and accounts for about 4 out of 10 people living with HIV in the Asia-Pacific region. There has been a $19 \%$ reduction in new HIV infections and a 38\% reduction in AIDS-related deaths in India between 2005 and 2013 [1]. However, estimates of HIV prevalence based on surveillance and other program data show that while most high HIV prevalence states in India have maintained a significant long-term decline in HIV prevalence, some traditionally low/moderate HIV prevalence states are showing an increasing trend in HIV prevalence [2]. The HIV epidemic in northeast Indiahas been primarily driven by injecting drug use since its inception in the late 1980s [3] [4]. Studies conducted in the two high HIV prevalence states of northeast India-Manipur and Nagaland-show that the HIV epidemic is concentrated among injecting drug users (IDUs) and female sex workers (FSWs) [5]-[7]. However, a recent study based on HIV Sentinel Surveillance (HSS) data from Nagaland shows an increasing trend in HIV prevalence among FSWs and men having sex with Men (MSM), while a declining trend is noted among IDUs [8], suggesting that the dynamics of the HIV epidemic in the northeastern region have changed over time.

Assam, a state located in the northeastern part of the country, is categorized as a low HIV prevalence state with an estimated adult HIV prevalence of $0.07 \%$, which is lower than the national prevalence of $0.27 \%$. However, adult HIV prevalence in the state has increased from $0.04 \%$ in 2007 to $0.07 \%$ in 2011 , and annual new HIV infections have increased from 1219 to 2408 over the corresponding period [9]. Assam is also a highly vulnerable state for HIV transmission as it is the gateway and commercial hub of northeast India, and shares a border with three high HIV prevalence states of Manipur, Mizoram and Nagaland [10]. HSS data from consistent sites in Assam during 2003-2011 reveal increasing HIV prevalence among antenatal clinic (ANC) attendees and FSWs, whereas IDUs showed a stable prevalence; sufficient data were not available for MSMs to ascertain a trend [11]. National Family Health Survey (NFHS) 2005-2006 data show that in Assam, just 49.6\% men and $23.9 \%$ women were aware that consistent condom use, which highlights low knowledge of HIV/AIDS compared to corresponding awareness at the national level $(68.1 \%$ men and $34.1 \%$ women) [12]. In view of the evolving HIV scenario in Assam, it is important to understand the geographical distribution and role of socio-cultural and programmatic factors which may have influenced the HIV scenario. This study aims to explore the geographical trend in HIV prevalence in the state, and its association with various developmental and programmatic factors. As literature on the HIV scenario in Assam is virtually non-existent, these findings will help in planning future programmatic interventions.

\section{Materials and Methods}

\subsection{Data}

A retrospective descriptive analysis of secondary data from the National AIDS Control Program(NACP) (e.g. Integrated Counseling and Testing Center (ICTC) data and Targeted Intervention project (TI) data, Census of India-2011, and District Level Household and Facility Survey-3 (2007-2008) was conducted. The period covered under the secondary data analysis was 2007 to 2012.

ICTC data: This data source included HIV positivity (\%), calculated from the number of HIV positive out of the number tested for HIV. ICTC data were used to study the trend in HIV prevalence during 2007 and 2012 by calculating the relative change in HIV positivity (\%) between the reference years. Increase of $>50 \%$ was classified as Category-I, increase of $<50 \%$ as category-II, and no change/decline as category-III. We included the ICTC HIV positivity (\%) data 2011 for bivariate analysis considering the proximity of the time period and availability of the independent variables.

Census of India data: From the 2011 Census of India, we included the female literacy rate, and the proportion of population using mobile phones and internet as independent variables for Assam state.

DLHS-3: We used data from DLHS-3 (2007-2008), which covered 27 districts of Assam. The independent variables included in our study from the DLHS-3 survey were: 1) women (15 - 49 years) with knowledge of consistent condom use for HIV prevention: Percentage of ever-married women aged 15 - 49 years who know that HIV can be prevented by using condoms; 2) Any government health facility in the district: percentage of 
villages in the district with any government health facility, including sub-center, primary health center, community health center, government hospital or dispensary; 3) women (15 - 49 years) using any method of modern contraception: Percentage of currently married women aged 15 - 49 years who are currently using any contraceptive method; 4) Women (15 - 49 years) seeking treatment for any sexually transmitted infection (STI)/reproductive tract infection (RTI): Percentage of ever-married women aged 15 - 49 years who sought treatment for any RTI/STI including abnormal vaginal discharge during the three months prior to the survey; 5) Women (15 49 years) having symptoms of STI/RTI: Percentage of ever-married women aged 15 - 49 years who reported any RTI/STI symptoms, including abnormal vaginal discharge, during the three months prior to the survey.

TI project data: We used 2011 data for female sex workers maintained by the TI projects in Assam. The independent variables included from the TI data were:1) Proportion of different typologies (home-based, brothel-based, street-based and lodge/dhaba-based) of FSWs: percentage of each typology in the district out of the total FSW population in the district; 2) Proportion of FSWs with different client load per week: we divided the number of clients per week into three categories: a) $<5$ clients per week; b) 5 - 9 clients per week; and c) $\geq 10$ clients per week. The percentage of FSWs in each category in the district out of the total population of FSW was used in the analysis; 3) Proportion of condomsutilized annually: Percentage of condoms utilized out of the total condoms supplied to the district in 2011.

\subsection{Ethical Statement}

The Assam State AIDS Control Society (ASACS), under the guidance of the National AIDS Control Organization (NACO), provided general oversight and approval for the collection and use of program data for examining the predictors of HIV prevalence in Assam. Verbal consent was taken from each client at the time of enrollment for HIV counseling and testing to use their medical history for research purposes. The Counselor at ICTC centers records all these procedures. Strict confidentiality of all the data was maintained, and no personal identifiers were included in the analysis. The use of secondary data and analyses in this study was reviewed and approved by the ethical review and data sharing committees of NACO, Government of India.

\subsection{Statistical Analysis}

The percentage relative change in HIV positivity during 2007 and 2012 was analyzed for all the districts and regions of Assam. Further, a trend analysis was done using chi-square for trend tests, and a p-value of $<0.05$ was considered statistically significant. Correlation analysis was done to examine the association between HIV prevalence and developmental and program indicators. All statistical analyses were conducted using SPSS software (version 16.0; SPSS, Chicago, IL, USA) and Epi-Info software.

\section{Results}

In Assam HIV testing is conducted at Integrated Counseling and Testing Centers (ICTC), which are located in medical colleges and district civil hospitals across all the districts of Assam, except Chirang district. During the study period, ICTC centers were scaled up across all the 27 districts of Assam (30 in 2007 to 83 in 2012) (Table 1).

From 2007 to 2012, HIV positivity (\%) increased relatively in North Assam (46.9\%), followed by South Assam (11.48\%) and East Assam (2.3\%) while there has been a relative decline in West Assam (-51.5\%). Overall, Dima-Hasao (962.5\%), Karbi-Anglong (445.0\%), Darrang (226.3\%), Dhemaji (200.0\%) and Nagaon (107.8\%) districts have shown significantly higher relative increase in HIV positivity (\%) from 2007 to 2012 in Assam (Table 2 and Figure 1).

In-depth analysis shows an increasing trend in HIV prevalence in East Assam (p-value: 0.000) and a declining trend in HIV prevalence in West Assam (p-value: 0.000). An increasing trend in HIV prevalence was also seen North and South Assam but this was not statistically significant. Correlation analysis of HIV positivity and selected variables shows that districts with higher HIV positivity (\%) have higher female literacy (p-value: 0.001 ) and higher internet usage (p-value: 0.006). Positive correlation of HIV positivity is also seen with percent of population using mobile phones and the availability of any government health facility in the district; however, this was not found to be statistically significant (Table 3).

Correlation analysis between HIV positivity (\%) and selected program indicators shows that districts with 


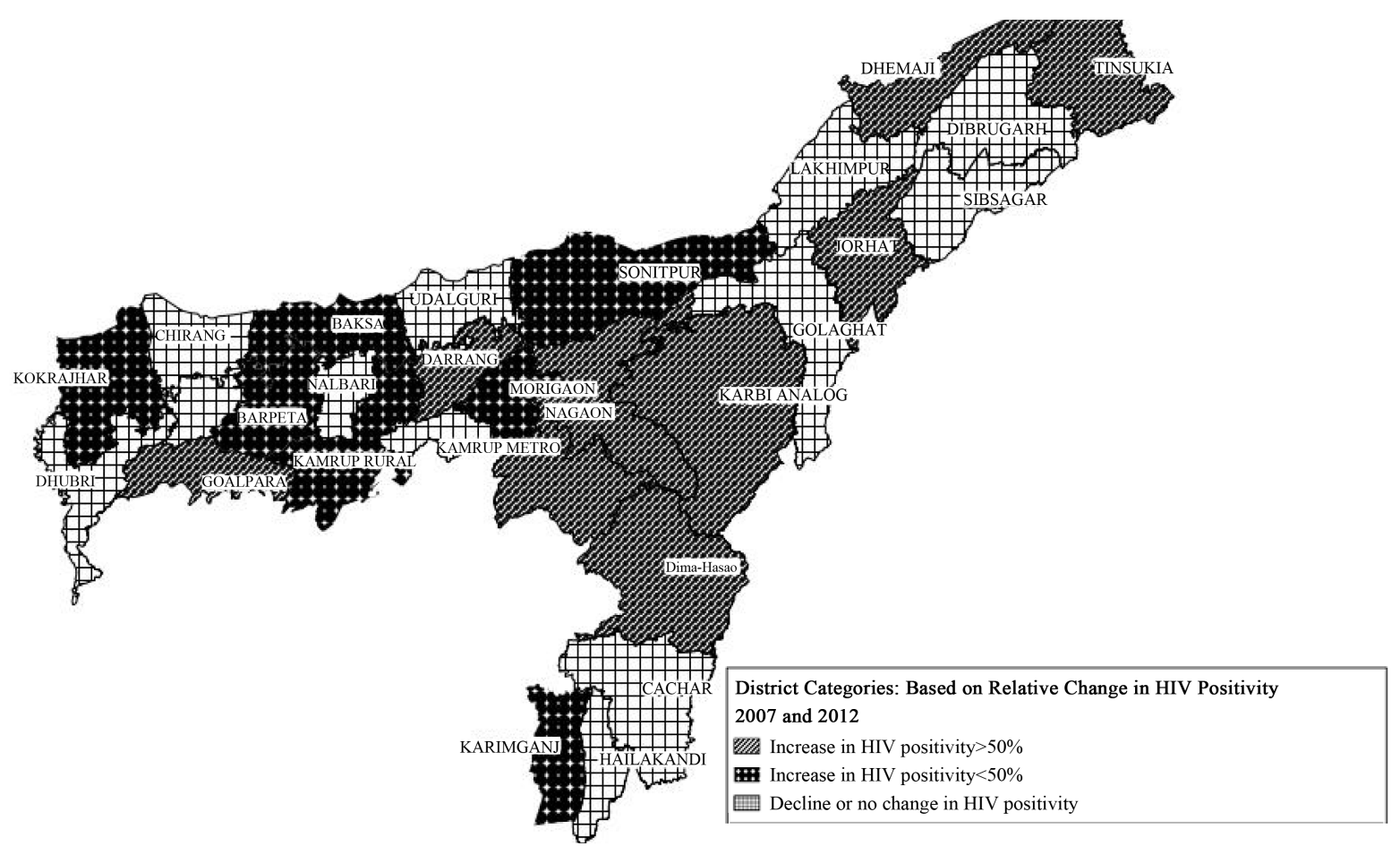

Figure 1. District map of Assam showing percentage relative change in HIV positivity during 2007-2012.

higher HIV positivity (\%) in 2011 had a higher proportion of women aged 15 - 44 years seeking treatment for any STI/RTI (p-value: 0.041), a higher proportion of brothel-based FSWs (p-value: 0.020), a lower proportion of FSWs with $<5$ clients/week (p-value: 0.000 ) and a higher proportion of annual condom utilization (p-value: 0.000). Additionally, districts with higher HIV positivity (\%) in 2011 had a lower proportion of home-based (correlation coefficient: -0.23 ) and lodge/dhaba-based (correlation coefficient: -0.27 ) FSWs; however, this is not statistically significant. Further, a negative correlation (correlation coefficient: -0.20 ) was observed between HIV positivity (\%) and the use of any modern method of contraception; however this was not statistically significant (Table 4).

Further correlation analysis between the typology of sex work and program indicators shows that among home-based FSWs, a higher proportion have 5 - 9 clients/week (p-value: 0.016). Moreover, districts with a higher proportion of street-based FSWs had a higher proportion of annual condom utilization (p-value: 0.025 ). A positive correlation with annual condom utilization is also seen among brothel-based FSWs while a negative correlation is noted among home and lodge/dhaba-based FSWs. However, these associations were not statistically significant. A positive correlation is also noted between home-based FSWs and women aged $15-44$ years with symptoms of STI/RTI, but this association is not statistically significant (Table 5).

\section{Discussion}

This study shows that during 2007-2012, HIV prevalence increased significantly in Dima-Hasao (962.5\%) and Karbi-Anglong (445.0\%) districts in south Assam, followed by Darrang (226.3\%) and Dhemaji (200.0\%) districts in north Assam and Nagaon (107.8\%) district in east Assam. A relative decline in HIV prevalence in west Assam is observed, although HIV prevalence has increased in some districts of the region. Recent rounds of HSS in the state also show higher HIV prevalence among ANC attendees in Dima-Hasao and Karbi-Anglong districts, while higher HIV prevalence was noted among FSWs in Darrang district [13]. A client audit study conducted in Assam during 2012 shows that around 15\% of all HIV-positive cases were from Nagaon district [14]. This study findings show a significant positive correlation between HIV positivity (\%) and female literacy in the districts of Assam. Other studies explain that higher education means higher health literacy, better knowledge and awareness of health services, and better access to health services like HIV testing services, resulting in more detection [15] [16]. Findings from the study also illustrate a positive correlation between HIV prevalence 
Table 1. Year-wise number of ICTCs by district, Assam, 2007-2012.

\begin{tabular}{|c|c|c|c|c|c|c|c|}
\hline Region & District & 2007 & 2008 & 2009 & 2010 & 2011 & 2012 \\
\hline \multirow{7}{*}{ East Assam } & Tinsukia & 1 & 1 & 2 & 2 & 2 & 3 \\
\hline & Jorhat & 1 & 2 & 2 & 2 & 2 & 3 \\
\hline & Morigaon & 1 & 2 & 2 & 2 & 2 & 2 \\
\hline & Golaghat & 1 & 2 & 3 & 3 & 3 & 4 \\
\hline & Sibsagar & 1 & 1 & 2 & 2 & 2 & 3 \\
\hline & Dibrugarh & 1 & 1 & 2 & 2 & 2 & 3 \\
\hline & Nagaon & 1 & 3 & 4 & 4 & 4 & 5 \\
\hline \multirow{10}{*}{ West Assam } & Goalpara & 1 & 2 & 2 & 2 & 3 & 3 \\
\hline & Kamrup & 2 & 5 & 7 & 7 & 7 & 7 \\
\hline & Baksa & 0 & 0 & 0 & 1 & 1 & 1 \\
\hline & Kokrajhar & 1 & 2 & 2 & 2 & 3 & 3 \\
\hline & Barpeta & 1 & 3 & 3 & 3 & 4 & 4 \\
\hline & Chirang & 0 & 0 & 0 & 0 & 0 & 0 \\
\hline & Nalbari & 1 & 3 & 3 & 3 & 3 & 3 \\
\hline & Kamrup(M) & 5 & 5 & 5 & 5 & 4 & 4 \\
\hline & Bongaigaon & 1 & 2 & 2 & 2 & 3 & 3 \\
\hline & Dhubri & 1 & 2 & 2 & 2 & 3 & 3 \\
\hline \multirow{5}{*}{$\begin{array}{l}\text { North } \\
\text { Assam }\end{array}$} & Dhemaji & 1 & 2 & 3 & 3 & 4 & 4 \\
\hline & Darrang & 1 & 2 & 2 & 2 & 3 & 3 \\
\hline & Sonitpur & 2 & 3 & 5 & 6 & 5 & 5 \\
\hline & Udalguri & 0 & 0 & 0 & 1 & 1 & 1 \\
\hline & Lakhimpur & 1 & 1 & 2 & 2 & 3 & 3 \\
\hline \multirow{5}{*}{ South Assam } & Dima-Hasao & 1 & 2 & 3 & 2 & 2 & 2 \\
\hline & Karbi-Anglong & 1 & 2 & 2 & 2 & 3 & 3 \\
\hline & Karimganj & 1 & 2 & 2 & 2 & 2 & 2 \\
\hline & Hailakandi & 1 & 2 & 2 & 2 & 2 & 2 \\
\hline & Cachar & 1 & 2 & 3 & 3 & 4 & 4 \\
\hline Total & Assam & 30 & 54 & 67 & 69 & 77 & 83 \\
\hline
\end{tabular}

and usage of internet and mobile phones. This relationship can be explained by the higher internet and mobile coverage in the bigger cities of Assam, like Guwahati, Dibrugarh and Silchar, which also have tertiary care health facilities conducting a high volume of HIV testing [17]. Studies also show that higher use of communication media, including the internet and mobile phones, increase knowledge and awareness as well as uptake of services [18] [19]. Our study also describe a significant association between HIV prevalence and the proportion of women (15 - 49 years) seeking STI/RTI treatment. Various studies have already established the epidemiological synergy between HIV and other STIs [20] [21]. It has also been seen that districts with better developmental indicators, including health seeking behavior, have higher HIV prevalence, maybe due to the higher volume of HIV testing and detection of cases. We see a significant correlation between HIV prevalence and the proportion of brothel-based FSWs. This finding is consistent with a study conducted in Karnataka on the typology of female sex worker, which reports a high rate of HIV and other STIs among brothel-based FSWs [22]. Other studies also show that brothel-based FSWs are more vulnerable to HIV transmission as they generally have clients from low-paid occupations, who are less inclined to use condoms and have high alcohol consumption [23]-[26]. 
Table 2. Percentage relative change in HIV positivity by district and region, Assam, 2007 and 2012.

\begin{tabular}{|c|c|c|c|c|c|c|}
\hline Region & District & $\begin{array}{c}\text { HIV } \\
\text { positivity } \\
(\%) \text { in } 2007\end{array}$ & $\begin{array}{c}\text { HIV } \\
\text { positivity } \\
(\%) \text { in } 2012\end{array}$ & $\begin{array}{c}\% \text { relative } \\
\text { change in } \\
\text { HIV } \\
\text { positivity } \\
\text { at district } \\
\text { level }\end{array}$ & $\begin{array}{c}\text { Category of } \\
\text { district }^{*}\end{array}$ & $\begin{array}{c}\% \text { relative } \\
\text { change in } \\
\text { HIV } \\
\text { positivity at } \\
\text { regional } \\
\text { level }\end{array}$ \\
\hline \multirow{7}{*}{ East } & Tinsukia & 0.0 & 0.86 & 86.0 & 1 & \multirow{7}{*}{2.30} \\
\hline & Jorhat & 0.5 & 0.94 & 88.0 & 1 & \\
\hline & Morigaon & 0.09 & 0.12 & 33.3 & 2 & \\
\hline & Golaghat & 0.91 & 0.58 & -36.3 & 3 & \\
\hline & Sibsagar & 0.31 & 0.28 & -9.7 & 3 & \\
\hline & Dibrugarh & 1.78 & 1.1 & -38.2 & 3 & \\
\hline & Nagaon & 0.77 & 1.6 & 107.8 & 1 & \\
\hline \multirow{10}{*}{ West } & Goalpara & 0.19 & 0.33 & 73.7 & 1 & \multirow{10}{*}{-51.5} \\
\hline & Kamrup & 0.0 & 0.11 & 11.0 & 2 & \\
\hline & Baksa & 0.0 & 0.08 & 8.0 & 2 & \\
\hline & Kokrajhar & 0.38 & 0.41 & 7.9 & 2 & \\
\hline & Barpeta & 0.26 & 0.27 & 3.8 & 2 & \\
\hline & Chirang & 0.0 & 0.0 & 0.0 & 3 & \\
\hline & Nalbari & 0.38 & 0.02 & -94.7 & 3 & \\
\hline & Kamrup(M) & 4.68 & 2.67 & -42.9 & 3 & \\
\hline & Bongaigaon & 1.07 & 0.52 & -51.4 & 3 & \\
\hline & Dhubri & 0.44 & 0.37 & -15.9 & 3 & \\
\hline \multirow{5}{*}{ North } & Dhemaji & 0.09 & 0.27 & 200.0 & 1 & \multirow{5}{*}{46.88} \\
\hline & Darrang & 0.19 & 0.62 & 226.3 & 1 & \\
\hline & Sonitpur & 0.65 & 0.73 & 12.3 & 2 & \\
\hline & Udalguri & 0.0 & 0.0 & 0.0 & 3 & \\
\hline & Lakhimpur & 0.42 & 0.07 & -83.3 & 3 & \\
\hline \multirow{5}{*}{ South } & Dima-Hasao & 0.08 & 0.85 & 962.5 & 1 & \multirow{5}{*}{11.48} \\
\hline & Karbi-Anglong & 0.2 & 1.09 & 445.0 & 1 & \\
\hline & Karimganj & 1.12 & 1.25 & 11.6 & 2 & \\
\hline & Hailakandi & 0.14 & 0.06 & -57.1 & 3 & \\
\hline & Cachar & 8.06 & 3.46 & -57.1 & 3 & \\
\hline
\end{tabular}

Note: ${ }^{*}$ Category 1: Increase in HIV positivity $>50 \%$, Category 2 : Increase in HIV positivity $<50 \%$, Category 3 : Decline or no change in HIV positivity; Relative change is the increase in percentage positive (PP) between 2007 and 2012 and calculated as (PP2012 - PP2007)/(PP2007) $\times 100$; Data source: ICTC data.

Our study could not show a definite relationship between HIV prevalence and FSWs' client load. However, a significant negative correlation is seen between HIV prevalence and the proportion of FSWs with less than 5 clients per week. Previous studies show higher HIV prevalence with higher client volume, generally resulting in inconsistent condom use [27] [28]. Thus, preventive efforts need to be strengthened, including condom distribution and use among FSWs with higher client volume. This study demonstrates a positive association between HIV prevalence and annual condom utilization. A recent study among MSM in China explains higher inconsistent utilization of condoms in vaginal sex compared to anal sex, which was significantly associated with HIV prevalence [29]. This may be because of the higher emphasis on use of condoms in anal sex, which may have weakened the understanding of the protective role of condoms in vaginal sex. 
Table 3. Correlation between HIV positivity (\%) and selected variables, Assam.

\begin{tabular}{|c|c|c|}
\hline \multirow{2}{*}{ Selected variables } & \multicolumn{2}{|c|}{ HIV positivity (\%) ${ }^{\circledR}$} \\
\hline & Correlation coefficient & p-value \\
\hline Female literacy ${ }^{\#}$ & 0.58 & $0.001^{* *}$ \\
\hline Percent of population using mobile phones ${ }^{\#}$ & 0.31 & 0.109 \\
\hline Percent of population using internet ${ }^{\#}$ & 0.51 & $0.006^{* *}$ \\
\hline $\begin{array}{c}\text { Women (15 - } 49 \text { yrs) aware that consistent condom } \\
\text { use prevents HIV }\end{array}$ & -0.05 & 0.781 \\
\hline Any govt. health facility in the district & 0.21 & 0.289 \\
\hline
\end{tabular}

Note: ${ }^{* *}$ Correlation is significant at 0.01 level. Source: ${ }^{\circledR}$ ICTC data (2011); ${ }^{*}$ Census of India-2011; ${ }^{\circ}$ DLHS-3 (2007-2008).

Table 4. Correlation between HIV positivity (\%) and selected program indicators, Assam.

\begin{tabular}{|c|c|c|}
\hline \multirow{2}{*}{ Variable } & \multicolumn{2}{|c|}{ HIV positivity (\%) ${ }^{\circledR}$} \\
\hline & Correlation coefficient & p-value \\
\hline Women (15 - 49 yrs) using any method of modern contraception ${ }^{\#}$ & -0.20 & 0.298 \\
\hline Women (15 - $49 \mathrm{yrs)}$ seeking treatment for any STI/RTI ${ }^{\#}$ & 0.40 & $0.041^{*}$ \\
\hline Women (15 - 49 yrs) with STI/RTI symptoms ${ }^{\#}$ & 0.41 & 0.839 \\
\hline Proportion of home-based FSWs & -0.23 & 0.239 \\
\hline Proportion of brothel-based FSWs & 0.44 & $0.020^{*}$ \\
\hline Proportion of street-based FSWs & 0.29 & 0.137 \\
\hline Proportion of lodge/hotel-based FSWs & -0.27 & 0.161 \\
\hline FSW with $<5$ clients/week & -0.49 & $0.008^{* *}$ \\
\hline FSWs with 5 - 9 clients/week & -0.27 & 0.164 \\
\hline FSWs with $\geq 10$ clients $/$ week & -0.27 & 0.170 \\
\hline Proportion of condoms utilized annually & 0.54 & $0.003^{* *}$ \\
\hline
\end{tabular}

Note: ${ }^{*}$ Correlation is significant at 0.05 level, ${ }^{* *}$ Correlation is significant at 0.01 level. Source: ${ }^{\circledR}$ ICTC data (2011); ${ }^{\wedge}$ TI data (2011); ${ }^{*}$ DLHS-3 (2007-2008).

As our study could not identify the definite causes of high HIV prevalence in spite of higher condom utilization, this issue should be explored in depth in future. However, preventive strategies should emphasis comprehensive understanding of safer sex and the protective role of condoms in all kinds of sexual behavior. Further, our analysis of program indicators by the different typologies of sex work shows a significant positive association between the proportion of street-based FSWs and annual condom utilization. This finding further substantiates the association between HIV prevalence and higher condom utilization, as it is seen that condom utilization has been higher among street-based FSWs in Assam and previous studies confirm that street-based FSWs are at higher risk of HIV transmission [30] [31]. We also found that annual condom utilization was lower among home-based and lodge/dhaba-based FSWs but the association was not statistically significant. Our study has certain limitations. First, while our study explores the association between HIV prevalence and different developmental and program indicators, it could not explain the underlying causes for these associations. Second, our analysis is limited to the variables that are available in the recorded data; further research could examine the range of factors associated with the evolving HIV scenario in Assam. This will require compilation of individual client-level program data from multiple sources, including health facilities and TI interventions, and will help in developing more concrete evidence-based programs.

\section{Conclusion}

This study reveals that HIV prevalence has increased significantly in some districts of Assam during 2007 and 
Table 5. Correlation between typology of female sex worker and program indicators, Assam.

\begin{tabular}{|c|c|c|c|c|c|}
\hline Program indicators & & $\begin{array}{c}\text { Proportion of } \\
\text { home-based } \\
\text { FSWs }\end{array}$ & $\begin{array}{c}\text { Proportion of } \\
\text { brothel-based FSWs }\end{array}$ & $\begin{array}{c}\text { Proportion of } \\
\text { street-based } \\
\text { FSWs }\end{array}$ & $\begin{array}{c}\text { Proportion of } \\
\text { lodge/ } \\
\text { dhaba-based } \\
\text { FSWs }\end{array}$ \\
\hline \multirow{2}{*}{$\begin{array}{l}\text { Women }(15-44 \text { yrs) with } \\
\text { symptoms of STI/RTI }\end{array}$} & $\begin{array}{l}\text { Correlation } \\
\text { coefficient }\end{array}$ & 0.35 & -0.02 & -0.32 & -0.02 \\
\hline & $\mathrm{p}$-value & 0.066 & 0.909 & 0.103 & 0.886 \\
\hline \multirow{2}{*}{$\begin{array}{c}\% \text { FSW with }<5 \\
\text { clients/week }\end{array}$} & $\begin{array}{l}\text { Correlation } \\
\text { coefficient }\end{array}$ & -0.09 & -0.20 & 0.00 & 0.20 \\
\hline & $\mathrm{p}$-value & 0.647 & 0.302 & 0.975 & 0.220 \\
\hline \multirow{2}{*}{$\begin{array}{l}\% \text { FSWs with } 5 \text { - } 9 \\
\text { clients/week }\end{array}$} & $\begin{array}{l}\text { Correlation } \\
\text { coefficient }\end{array}$ & 0.45 & -0.23 & -0.44 & 0.10 \\
\hline & p-value & $0.016^{*}$ & 0.233 & $0.021^{*}$ & 0.620 \\
\hline \multirow{2}{*}{$\begin{array}{l}\% \text { FSWs with } \geq 10 \\
\text { clients/week }\end{array}$} & $\begin{array}{l}\text { Correlation } \\
\text { coefficient }\end{array}$ & 0.03 & -0.13 & -0.03 & 0.05 \\
\hline & p-value & 0.875 & 0.519 & 0.873 & 0.800 \\
\hline \multirow{2}{*}{$\begin{array}{l}\text { Proportion of condoms } \\
\text { utilized annually }\end{array}$} & $\begin{array}{l}\text { Correlation } \\
\text { coefficient }\end{array}$ & -0.35 & 0.18 & 0.43 & -0.26 \\
\hline & p-value & 0.069 & 0.363 & $0.025^{*}$ & 0.181 \\
\hline
\end{tabular}

Note: ${ }^{*}$ Correlation is significant at 0.05 level; Source: ^TI data (2011); " DLHS-3 (2007-2008).

2012, and these geographical areas will require increased programmatic focus like increasing HIV testing among the high risk groups and general population, regular screening of high risk groups and bridge population for different STI/RTIs, etc. Further, it will be essential to develop district specific strategies for these key districts as the vulnerabilities may vary from district to district. The study also highlights that higher HIV prevalence is associated with improved developmental indicators, suggesting the important role played by increased awareness, accessibility to health services and communication media in the scale up of HIV services. The program may consider the use of media like SMS and social media, to increase awareness and promote treatment adherence with specific priority to the districts with rising HIV prevalence. This study also illustrates that HIV prevalence is high in spite of high annual condom utilization, highlighting the need to strengthen preventive strategies to ensure consistent condom use among high-risk groups. Further, the program will also have to devise strategies for increasing condom use among home-based and lodge/dhaba-based FSWs. This study recommends for further research and advocacy based evidence to ensure that these issues are properly addressed. The finding of this study may be also applicable to other states in Northeastern India like Meghalaya and Tripura which have shown similar rise in HIV prevalence and incidence in recent years. However, further research is needed as vulnerabilities may vary from state to state.

\section{Acknowledgements}

This paper (NACO/SIMU/NDAP/2015/03) was written as part of the National Data Analysis Plan, an initiative of Strategic Information Management Unit of National AIDS Control Organization (NACO), Ministry of Health and Family Welfare, Government of India. We would like to thank the various divisions of NACO and State AIDS Control Society (SACS) that have collected and maintained the program data. This paper was conceptualized, developed and finalized by the author, under the guidance of mentors (senior public health experts) and the National Data Analysis Plan (NDAP) Unit, NACO. The Knowledge Network project of the Population Council, which is a grantee of the Bill \& Melinda Gates Foundation though Avahan, the India AIDS Initiative, has supported the scientific writing, reviewing, editing and finalization of this paper. This project was also supported by NACO's other development partners, which include Center for Diseases Control (CDC), World Health Organization-India, FHI-360, and John Snow India. The views expressed in this paper are those of the authors, and do not necessarily reflect the views of NACO. 


\section{References}

[1] Joint United Nations Programme on HIV/AIDS (2014) GAP Report. Geneva.

[2] Pandey, A., Sahu, D., Bakkali, T., et al. (2012) Estimate of HIV Prevalence and Number of People Living with HIV in India 2008-2009. BMJ Open, 2, e000926. http://dx.doi.org/10.1136/bmjopen-2012-000926

[3] ISHA (2014) HIV-AIDS Situation in North Eastern States. Indian Society for Health Administrators. www.medind.nic.in/haa/t04/i1/haat04ilp147.pdf

[4] Sarkar, S., Das, N., Panda, S., et al. (1993) Rapid Spread of HIV among Injecting Drug Users in North-Eastern States of India. Bulletin on Narcotics, 45, 91-105.

[5] Lucas, G.M., Solomon, S.S., Srikrishnan, A.K., et al. (2015) High HIV Burden among People Who Inject Drugs in 15 Indian Cities. AIDS, 29, 619-28. http://dx.doi.org/10.1097/qad.0000000000000592

[6] Medhi, G.K., et al. (2012) Factors Associated with History of Drug Use among Female Sex Workers (FSW) in a High HIV Prevalence State of India. BMC Public Health, 12, 273. http://www.biomedcentral.com/1471-2458/12/273 http://dx.doi.org/10.1186/1471-2458-12-273

[7] Medhi, G.K., Mahanta, J., Hazarika, I., et al. (2013) Syphilis Infection among Female Sex Workers in Nagaland, Northeast India: Analysing Their Vulnerability to the Infection. International Journal of STD \& AIDS, 24, 193. http://dx.doi.org/10.1177/0956462412472427

[8] Saha, M.K., Mahapatra, T., Biswas, S., et al. (2015) Burden and Correlates of HIV Risk among Men Who Have Sex with Men in Nagaland, India: Analysis of Sentinel Surveillance Data. PLoS ONE, 10, e0117385. http://dx.doi.org/10.1371/journal.pone.0117385

[9] National AIDS Control Organization (2012) Technical Report on India HIV Estimates. New Delhi.

[10] Assam State AIDS Control Society (2015) HIV Scenario in Assam. Guwahati.

[11] Assam State AIDS Control Society (2012) State Surveillance Report 2010-11. Guwahati.

[12] National Family Health Survey, India (2005) Assam Factsheet. http://www.rchiips.org/nfhs/factsheet.shtml

[13] Assam State AIDS Control Society (2014) State Surveillance Report 2012-13. Guwahati.

[14] Assam State AIDS Control Society (2013) Clinical Audit of Client Data. Guwahati.

[15] Park, J.N., Papworth, E., Billong, S.C., et al. (2014) Correlates of Prior HIV Testing among Men Who Have Sex with Men in Cameroon: A Cross-Sectional Analysis. BMC Public Health, 14, 1220. http://dx.doi.org/10.1186/1471-2458-14-1220

[16] Easton, P., Entwistle, V.A. and Williams, B. (2010) Health in the "Hidden Population" of People with Low Literacy. A Systematic Review of the Literature. BMC Public Health, 10, 459.

[17] Assam State AIDS Control Society (2015) HIV/AIDS Factsheet of Assam. Guwahati.

[18] Scanlon, M.L. and Vreeman, R.C. (2013) Current Strategies for Improving Access and Adherence to Antiretroviral Therapies in Resource Limited Settings. HIV/AIDS-Research and Palliative Car, 5, 1-17.

[19] Gold, J., Lim, M.S.C., Hellard, M.E., et al. (2010) What's in a Message? Delivering Sexual Health Promotions to Young People in Australia via Text Messaging. BMC Public Health, 10, 792. http://dx.doi.org/10.1186/1471-2458-10-792

[20] Wasserheit, J.N. (1992) Epidemiological Synergy. Interrelationships between Human Immunodeficiency Virus Infection and Other Sexually Transmitted Diseases. Sexually Transmitted Diseases, 19, 61-77. http://dx.doi.org/10.1097/00007435-199219020-00001

[21] Clottey, C. and Dallabetta, G. (1993) Sexually Transmitted Diseases and Human Immunodeficiency Virus. Epidemiologic Synergy? Infectious Disease Clinics of North America, 7, 753-770.

[22] Buzdugan, R., Copas, A., Moses, S., et al. (2010) Devising a Female Sex Work Typology Using Data from Karnataka, India. International Journal of Epidemiology, 39, 439-448. http://dx.doi.org/10.1093/ije/dyp351

[23] Dandona, R., Dandona, L., Gutierrez, J.P., et al. (2005) High Risk of HIV in Non-Brothel Based Female Sex Workers in India. BMC Public Health, 5, 87. http://dx.doi.org/10.1186/1471-2458-5-87

[24] Madhivanan, P., Hernandez, A., Gogate, A., et al. (2005) Alcohol Use by Men Is a Risk Factor for the Acquisition of Sexually Transmitted Infections and Human Immunodeficiency Virus from Female Sex Workers in Mumbai, India. Sexually Transmitted Diseases, 32, 685-690. http://dx.doi.org/10.1097/01.olq.0000175405.36124.3b

[25] Rodr'iguez, D.C., Krishnan, A.K., Kumarasamy, N., et al. (2010) Two Sides of the Same Story: Alcohol Use and HIV Risk Taking in South India. AIDS and Behavior, 14, 136-146. http://dx.doi.org/10.1007/s10461-010-9722-z

[26] Samet, J.H., Pace, C.A., Cheng, D.M., et al. (2010)Alcohol Use and Sex Risk Behaviors among HIV-Infected Female Sex Workers (FSWs) and HIV-Infected Male Clients of FSWs in India. AIDS and Behavior, 14, 74-83. 
http://dx.doi.org/10.1007/s10461-010-9723-y

[27] Hemlata, R., Harikumar, R., Venkaiah, K., et al. (2011) Prevalence of \& Knowledge, Attitude \& Practices towards HIV \& Sexually Transmitted Infections (STIs) among Female Sex Workers (FSWs) in Andhra Pradesh. Indian Journal of Medical Research, 134, 470-475.

[28] Bradley, J., Rajaram, S., Moses, S., et al. (2013) Female Sex Worker Client Behaviors Lead to Condom Breakage: A Prospective Telephone-Based Survey in Bangalore, South India. AIDS and Behavior, 17, 559-567. http://dx.doi.org/10.1007/s10461-012-0192-3

[29] Gao, W., Li, Z.Q., Li, Y. and Qiao, X.W. (2015) Sexual Practices and the Prevalence of HIV and Syphilis among Men Who Have Sex with Men in Lanzhou, China. Japanese Journal of Infectious Diseases. (Advance Publication) http://dx.doi.org/10.7883/yoken.JJID.2013.477

[30] Jain, A.K. and Saggurti, N. (2012) The Extent and Nature of Fluidity in Typologies of Female Sex Work in Southern India: Implications from HIV Prevention Programs. Journal of HIV/AIDS \& Social Sciences, 11, 169-191. http://dx.doi.org/10.1080/15381501.2012.678136

[31] Ramesh, B.M., Beattie, T.S.H., Shajy, I., et al. (2010) Changes in Risk Behaviors and Prevalence of Sexually Transmitted Infections Following HIV Preventive Interventions among Female Sex Workers in Five Districts in Karnataka State, South India. Sexually Transmitted Infections, 86, i17-i24. http://dx.doi.org/10.1136/sti.2009.038513

\section{List of Abbreviations Used in the Paper}

\begin{tabular}{cc}
\hline FSW & Female Sex Worker \\
MSM & Men having Sex with Men \\
IDU & Injecting Drug User \\
ANC & Antenatal Clinic Attendee \\
NACP & National AIDS Control Program \\
ICTC & Integrated Counseling and Testing Center \\
TI & Targeted Intervention \\
DLHS & District Level Household and Facility Survey \\
STI/RTI & Sexually Transmitted Infection/Reproductive Tract Infection \\
NACO & National AIDS Control Organization \\
ASACS & Assam State AIDS Control Society \\
\hline
\end{tabular}

